\title{
Leaf Senescence of Postproduction Poinsettias in Low-light Stress
}

\author{
J. Lorene Embry ${ }^{1}$ and Eugene A. Nothnagel \\ Department of Botany and Plant Sciences, University of California, Riverside, CA 92521
}

Additional index words. Euphorbia pulcherrima, photosynthesis, chlorophyll fluorescence, light harvesting

\begin{abstract}
Photosynthetic light harvesting was investigated under low-light stress conditions relevant to the problem of interior longevity of potted ornamental plants. Comparisons of leaf pigment levels and chlorophyll fluorescence excitation spectra were made for 'Gutbier V-10 Amy' poinsettia (Euphorbia pulcherrima Willd.), which has poor interior longevity, and 'Eckespoint Lilo' poinsettia, which has superior interior longevity. The results show that 'Eckespoint Lilo' had higher total chlorophyll content per leaf area and lower chlorophyll a : chlorophyll b ratio than ' Gutbier V-10 Amy'. In low-light stress, 'Eckespoint Lilo' retained its chlorophyll or even accumulated higher levels than in high light, while 'Gutbier V10 Amy' did not exhibit higher chlorophyll retention in low light. Both cultivars acclimatized to low-light stress by decreasing the chlorophyll a : chlorophyll b ratio, and this acclimatization was evident sooner in younger, outer-canopy leaves above the pinch than in older leaves below the pinch. Both cultivars also increased the chlorophyll : carotenoid ratio in low light. These changes in pigment composition, which were essentially structural changes, were reflected in functional changes in light harvesting, as assessed by measurements of chlorophyll fluorescence excitation spectra.
\end{abstract}

Interior longevity of potted ornamental plants is a point of practical concern for consumers and thus a point of economic concern for producers. Many environmental variables differ between a greenhouse, the typical production site, and the interiors of homes or offices, the typical consumption sites. Since maximum light levels in many homes and offices are no more than $5 \%$ of those in greenhouses, low-light stress is likely among the most important environmental factors influencing interior longevity. In the present project, the poinsettia was used as an economically important model system to investigate low-light stress effects on photosynthetic pigments and light harvesting.

Previous investigators have shown that low-light stress has deleterious effects on the postproduction performance of poinsettias. Most of these previous studies (Miller and Heins, 1986a, 1986b; Nell and Barrett, 1990; Scott et al., 1984a, 1984b; Shanks et al., 1970) focused on leaf and/or cyathia abscission and did not examine photosynthetic pigments or involved only visual estimates of loss of green from the leaves. In one of these studies (Nell and Barrett, 1990), four poinsettia cultivars were compared for leaf abscission under typical indoor conditions. 'Eckespoint Lilo' exhibited the lowest leaf drop of the four cultivars tested. In another experiment, leaf abscission in 'Dark Red Annette Hegg' and 'Gutbier V-14 Glory' increased as the interior light level decreased or as the interior temperature increased. No data regarding leaf photosynthetic pigments were reported.

Investigators in two studies (Nell and Barrett, 1986; Nell et al., 1990) recognized the importance of photosynthesis in the postharvest period and addressed this aspect of physiology by measuring the light compensation points and dark respiration rates in cultivars that differ in interior longevity. These two physiologi-

Received for publication 7 Sept. 1993. Accepted for publication 9 Dec. 1993. This work was initially supported by an Intramural Research Grant from the Univ. of California and subsequently sustained by grants from the California Association of Nurserymen and the California Department of Food and Agriculture. We thank the Paul Ecke Poinsettia Ranch for providing rooted poinsettia cuttings, David Hartley for advice on poinsettia production and for reviewing the manuscript, Ursula Schuch for reviewing the manuscript, Van Stout for designing and constructing the shade boxes, and Dolores Archer for technical assistance. The cost of publishing this paper was defrayed in part by the payment of pages charges. Under posta regulations, this paper therefore must be hereby marked advertisement solely to indicate this fact.

${ }^{1}$ Deceased. cal parameters did not differ between the cultivars and were therefore concluded to be poor indicators of interior longevity (Nell et al., 1990). Several recent studies have shown that poinsettias can be acclimatized by decreased light levels during certain portions of the production period. This acclimatization was manifested in the postproduction period as increased carbon exchange rate and decreased leaf abscission, but increased cyathia abscission (Bailey and Miller, 1991; Nell and Barrett, 1986; Nell et al., 1990). Also relevant to photosynthetic performance is the observation (Scott et al., 1984a) that senescence of poinsettias was slower under incandescent tungsten lamps than under fluorescent lamps.

The objective of this study was to examine parameters relevant to photosynthetic light harvesting in poinsettias exposed to lowlight stress during the postproduction period. The study was enhanced by the comparison of two cultivars that differ in interior performance. The first approach in the study was to determine the amounts of photosynthetic pigments in the leaves under different light levels during the postproduction period. Although the emphasis was on the chlorophylls as the most important light-harvesting pigments, the relative level of carotenoid pigments was also examined since these pigments likewise contribute to light harvesting for photosynthesis (Siefermann-Harms, 1985, 1987). Leaves below and above the pinch were examined, since the lower leaves tend to senesce first but the outer canopy leaves are more visible to the consumer and may respond differently because of their younger age.

The second approach involved measurements of excitation, or action, spectra for the generation of chlorophyll fluorescence. At $25 \mathrm{C}$ in the presence of 3-(3,4-dichlorophenyl)-1,1-dimethylurea, most of this fluorescence arises from chlorophyll a in the photosystem II reaction center, although a small contribution from photosystem I cannot be ruled out when fluorescence emission is measured at $734 \mathrm{~nm}$ as in the present work (Goedheer, 1972; Hipkins and Baker, 1986; Percival and Baker, 1985). The shape of the fluorescence excitation spectrum thus reflects the combined effectiveness of all of the pigments in the antenna system that absorb incident light and transfer excitation energy to the photosynthetic reaction centers (Butler, 1961; Fradkin et al., 1985; Goedheer, 1965; Koizumi et al., 1990; Siefermann-Harms, 1985, 1987; Vertucci et al., 1985). While the pigment contents determined through the first approach can be considered structural information, the fluorescence excitation spectra measured through 
the second approach indicate the functional effectiveness of these pigments.

\section{Materials and Methods}

Plant material and growth conditions. Rooted cuttings of poinsettia (Euphorbia pulcherrima Willd.) cultivars Gutbier V-10 Amy ('Amy') and Eckespoint Lilo ('Lilo') were supplied by the Paul Ecke Poinsettia Ranch (Encinitas, Calif.). 'Amy' is a poor interior performer, and 'Lilo' is a good interior performer (David Hartley, personal communication; Nell et al., 1990; Nell and Barrett, 1986, 1990). One cutting was transplanted per $15 \mathrm{~cm}$ in diameter plastic pot containing Sunshine mix \#1 medium(Western Peat Moss Ltd., Vancouver, B.C.). A few days after transplanting, each pot was fertilized with $9 \mathrm{~g}$ Osmocote $12 \mathrm{~N}-5.2 \mathrm{P}-12.5 \mathrm{~K}$ (Sierra Chemical Company, Milpitas, Calif.). The potted plants were placed on a greenhouse bench under natural lighting that was typically 950 to $1300 \mu \mathrm{mol} \cdot \mathrm{m}^{-2} \cdot \mathrm{s}^{-1}$ at canopy level at midday. For the first 4 weeks of establishment, however, an overhead shade cloth was used to attenuate the natural lighting by $66 \%$. An automatic timer controlled irrigation with water through tubes that were positioned on the surface of the potting medium. Greenhouse thermostats were set for 20C nights and 27C days. Measured temperatures were 18 to $22 \mathrm{C}$ nights and typically 23 to $29 \mathrm{C}$ days, although midday temperatures in summers sometimes reached 35C. In experiments run from October through March, supplemental light (100-W incandescent lamps located $1 \mathrm{~m}$ above canopy level at 1-m intervals along the length of the bench) was provided throughout nights to prevent premature flower initiation in young plants.

Apex pruning and leaftagging below the pinch. At 4 weeks after transplanting, the shade cloth was removed and the apex was pruned to leave eight fully expanded leaves below the pinch. On 55 plants of each cultivar in each experiment, a marker tag was attached to the petiole of the second leaf below the pinch, and these tagged leaves were later harvested for leaf pigment and chlorophyll fluorescence analyses.

Controlling photoperiod for flower initiation. Beginning at 1 week after plants were pinched and continuing for 7 weeks, the photoperiod was controlled to provide 14-h dark periods beginning daily at $1600 \mathrm{HR}$. This treatment to induce flowering and bract coloring was accomplished with an automated system that drew an opaque curtain over the greenhouse bench. An electric fan positioned under the bench and ducted through the curtain provided air exchange when the curtain was drawn over the bench.

Leaf tagging above the pinch and low-light treatment. After 7 weeks of photoperiod control and then 2 weeks of natural photoperiod, the plants were in full flower. Each plant then received a second marker tag which was placed on the petiole of a leaf above the pinch. A green leaf was selected on a flowering branch in the outer canopy, two leaves below the lowest red color. Five plants of each cultivar were set aside for the harvest representing time 0 of the shade treatment. Twenty-five plants of each cultivar were numbered and left on the open bench as high-light controls, and 25 plants were numbered and placed on the adjacent, low-light bench. This procedure provided five pre-identified plants of each cultivar in each treatment for the subsequent harvests at 7, 14, 21, 28, and 35 days.

Shade boxes provided the low-light environment on the adjacent greenhouse bench. Each shade box was $234 \times 142 \times 71 \mathrm{~cm}(1$ $\times \mathrm{w} \times \mathrm{h}$ ), and two boxes covered an entire bench. Two layers of fabric, with a separating gap of $5 \mathrm{~cm}$, formed the ceiling and walls of each box. The fabric from Phifer Western (City of Industry,

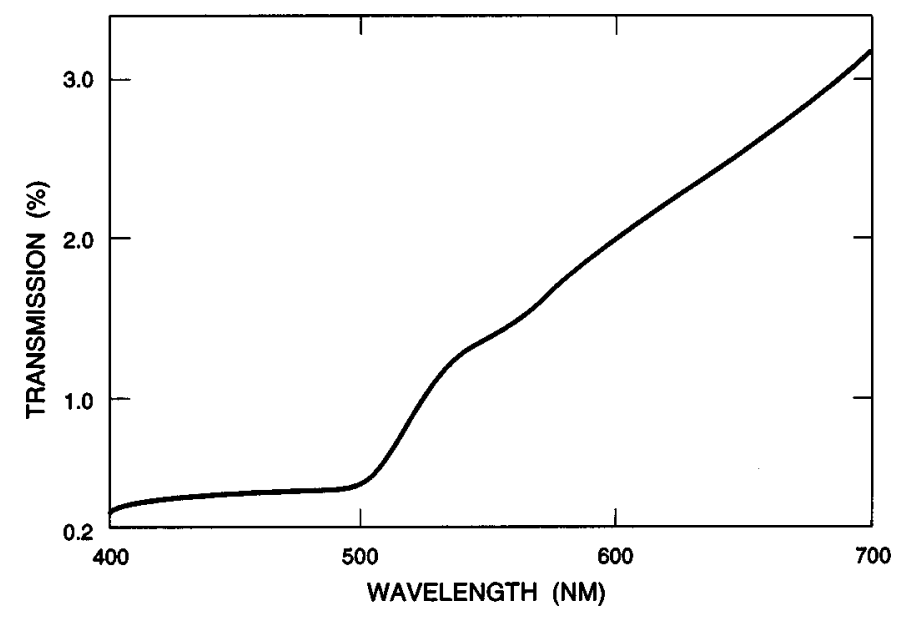

Fig. 1. Transmission spectrum of shade box used to expose poinsettias to low-light stress. The average of 30 scans of light intensity at 10 locations inside the box was divided by the average of 30 scans of light intensity at 10 locations just outside the box.

Calif.) was a $34 \times 11$ weave of almond-colored, vinyl-coated polyester threads. Light intensities inside the shade boxes were approximately $10 \mu \mathrm{mol} \cdot \mathrm{m}^{-2} \cdot \mathrm{s}^{-1}$ at midday. The spectral transmission of the boxes was measured with a portable spectroradiometer (model LI-1800; LI-COR, Lincoln, Neb.). The shade boxes were especially effective in attenuating the shorter wavelengths (Fig. 1), thus simulating indoor incandescent lighting better than fluorescent lighting. Two $7 \mathrm{~m}^{3} \cdot \mathrm{min}^{-1}$ fans, located in diagonally opposite corners, blew air through attenuating diffusers into each box to exchange the air approximately two times per minute. This continuous air exchange insured that temperature, humidity, and gas concentrations in the box were similar to those experienced by the high-light control plants on the adjacent open bench.

Recording leaf abscission. At the beginning of the shade treatment (day 0) and on the five subsequent harvest dates, all of the main stem leaves remaining below the pinch on the five plants to be harvested that day were counted, and the percent abscission was determined.

Harvesting leafdisks. On day 0 of the shade treatment, disks 12 mm in diameter were punched midway between the center vein and the margin of the leaves on five plants of each cultivar. Two sets of disks per cultivar were harvested from the tagged leaves below the pinch, and two more sets from the tagged leaves above the pinch. Five disks per sample were combined, weighed, chopped into $2-\mathrm{mm}^{2}$ pieces, and frozen in test tubes on dry ice at the greenhouse bench. Similar dual harvests were made on each of the subsequent dates.

Extracting and quantitating pigments directly from leaf tissue. Chopped leaf samples were held on dry ice in the dark for no more than $24 \mathrm{~h}$ before leaf pigments were extracted and quantitated. One of the dual sets of five chopped leaf disks was ground in $5 \mathrm{ml}$ acetone for 1 min with a Biohomogenizer (Biospec Products, Bartlesville, Okla.). Three $\mathrm{ml}$ acetone, used to rinse the homogenizer probe, and $2 \mathrm{ml}$ water were pooled with the ground leaf tissue to total $10 \mathrm{ml}$. The extract was centrifuged at $13,000 \times g$ for $10 \mathrm{~min}$, and the supernatant was filtered through a polytetrafluoroethylene membrane having $0.2-\mu \mathrm{m}$ pores (Acrodisc 13CR PTFE from Gelman Sciences, Ann Arbor, Mich.). Absorbances of the filtrate were measured at 460, 645, and $663 \mathrm{~nm}$ against a blank of $80 \%$ (by volume) acetone in water. Concentrations of chlorophyll $\mathrm{a}$, chlorophyll b, and total carotenoids were calculated from the 
absorbances (Embry and Nothnagel, 1988).

Preparing a thylakoid membrane fraction. The second set of five chopped leaf disks was processed to obtain a thylakoid membrane fraction. The method of Percival and Baker (1985), used by us to prepare millet thylakoids (Embry and Nothnagel, 1988), was slightly modified to accommodate the large amount of milky latex present in aqueous homogenates of poinsettia leaf tissue. The filtrate obtained by passing the homogenate through a nylon net (Embry and Nothnagel, 1988) was centrifuged at 13,000x $g$ for $90 \mathrm{sec}$, instead of the $3000 \times g$ for $90 \mathrm{sec}$ used for millet. The pellet thus obtained from five chopped leaf disks was resuspended in $0.5 \mathrm{ml}$ resuspension buffer consisting of $100 \mathrm{~mm}$ sorbitol, $5 \mathrm{~mm}$ $\mathrm{NaCl}, 5 \mathrm{~mm} \mathrm{MgCl}_{2}$, and $10 \mathrm{~mm} N$-2-hydroxyethylpiperazine- $N$ '-2ethanesulfonic acid at $\mathrm{pH}$ 7.0. This thylakoid suspension was supplemented with glycerol to $15 \%$ (by volume) and then stored frozen in the dark at liquid nitrogen temperature until analyzed.

Analyzing pigment ratios and chlorophyll fluorescence in thylakoids. While chlorophyll fluorescence can be measured directly from intact leaf tissue, the chlorophyll concentration in leaves is so high that much of the emitted fluorescence is reabsorbed by other chlorophyll molecules before it can escape the leaf. Because this reabsorption is wavelength dependent, chlorophyll fluorescence spectra obtained from intact leaves are strongly distorted (Percival and Baker, 1985). This artifact was avoided in the present study by using thylakoid membrane suspensions at concentrations sufficiently dilute that reabsorption was negligible.

Thylakoid membrane preparations in vials were removed from the liquid nitrogen freezer and quickly thawed by immersion in warm water. The suspension was removed from the vial, diluted by adding at least nine volumes of resuspension buffer, centrifuged at $13,000 \times g$ for $90 \mathrm{sec}$, and resuspended in $0.5 \mathrm{ml}$ resuspension buffer. Pigment concentrations in this thylakoid suspension were determined by drawing a $25-\mu$ l aliquot, extracting it with $80 \%$ (by volume) acetone, passing the extract through a filter (Acrodisc 13CR PTFE, German Sciences, Ann Arbor, Mich.), and measuring absorbances as described above for pigments extracted directly from leaf tissue. A further aliquot from the thylakoid suspension was mixed with appropriate amounts of resuspension buffer and 3(3,4-dichlorophenyl)-1,1-dimethylurea (10 mM stock in ethanol) to obtain a suspension with total chlorophyll at $2 \mu \mathrm{g} \cdot \mathrm{ml}^{-1}$ and 3(3,4-dichlorophenyl)-1,1-dimethylurea at $20 \mu \mathrm{M}$.

Fluorescence excitation spectra were measured at $25 \mathrm{C}$ with a spectrofluorometer (model 112A Fluorolog 2; Spex Industries, Edison, N.J.). Slit widths of $2.50 \mathrm{~mm}$ were used and resulted in 9.2 $\mathrm{nm}$ bandpass resolution in the single excitation spectrometer and $4.5 \mathrm{~nm}$ bandpass resolution in the double emission spectrometer. Excitation spectra were corrected for variation in excitation energy and differences in optical paths by use of $1,1^{\prime}, 3,3,3^{\prime}, 3^{\prime}$ hexamethylindotricarbocyanine perchlorate as a quantum counter dye (Nothnagel, 1987). A colored-glass filter (model KG-3; FishSchurman Corp., New Rochelle, N.Y.) was used in the excitation path to attenuate stray light from the very strong near-infrared emission lines of the Xe (model XBO 150 W/l; Osram Corp., Montgomery, N.Y.) arc lamp (Nothnagel, 1987). Stray and scattered light were further reduced by a 700-nm short-wave pass interference filter (model 700FL07-50; Andover Corp., Salem, N.H.) that was used in the excitation path, and a 730-nm long-wave pass colored-glass filter (model RG-9; Schott Optical Glass, Duryea, Pa.) that was used in the emission path.

The thylakoid suspensions were held in $1 \times 1 \times 4.5$-cm polystyrene cuvettes during the fluorescence measurements and were magnetically stirred to prevent settling. When the $2.50-\mathrm{mm}$ excitation slits were used, the excitation spectrometer illuminated a 3.3 $\times 8.0-\mathrm{mm}$ area on the front face of the cuvette. As the excitation spectrometer was scanned from 400 to $700 \mathrm{~nm}$, the incident light intensity in this illuminated area varied between 60 and 230 $\mu \mathrm{mol} \cdot \mathrm{m}^{-2} \cdot \mathrm{s}^{-1}$, with the integrated average being $160 \mu \mathrm{mol} \cdot \mathrm{m}^{-2} \cdot \mathrm{s}^{-1}$. Front-face collection of emitted light, i.e., collection at an angle of $22.5^{\circ}$ relative to the incident beam, was used to further minimize reabsorption artifacts. Chlorophyll fluorescence emission was measured at $734 \mathrm{~nm}$ in the band arising from vibrational sublevels in the main chlorophyll transition (Goedheer, 1972).

The thylakoid suspensions, which had been held in the dark, were pre-illuminated in the spectrofluorometer for $40 \mathrm{sec}$ before initiating the excitation scan. Control experiments involving fluorescence measurements at fixed excitation and emission wavelengths showed that specimens containing 3-(3,4-dichlorophenyl)1,1-dimethylurea and preilluminated as described exhibited no time-dependent fluorescence induction kinetics over a time period equal to that required to complete an excitation scan.

Before summing for average, excitation spectra were normalized to unit area intensity integrated between 400 and $700 \mathrm{~nm}$. Differences between cultivars or between plants at different times and conditions were highlighted by expressing the excitation spectra as difference spectra. For these calculations, the excitation spectrum for thylakoids from leaves below the pinch of 'Lilo' at day 0 was scaled to relative intensity of 100 at the long wavelength peak that occurred in the 660 to $680 \mathrm{~nm}$ range. The area intensity of this spectrum integrated between 660 and $680 \mathrm{~nm}$ was then used as the standard. Before subtracting to obtain difference spectra, all other spectra were scaled so their area intensities integrated between 660 and $680 \mathrm{~nm}$ matched that of the standard.

Combining results from separate experiments. Data reported for leaves below the pinch were the combined results from three experiments conducted in separate years (cutting transplant dates 15 Nov. 1989, 17 July 1990, and 29 Jan. 1991). Data for leaves above the pinch were not recorded in the first experiment, so the reported data were the combined results from two experiments. Data on the time course of changes in leaf abscission and pigment levels involved discrete measurements that were amenable to statistical analysis. Analysis of variance and the F test of significance were performed with the InStat program (GraphPad Software, San Diego, Calif.) for personal computers. Fisher's LSD (Dowdy and Weardon, 1983) was subsequently calculated at $P=0.05$.

\section{Results}

The two poinsettia cultivars selected for this study had been previously judged as inferior ('Amy') and superior ('Lilo') performers in interior conditions where several environmental variables differ from a greenhouse. When abscission of main stem leaves below the pinch was examined in a comparison where light was the only (within the limits of our experimental abilities) environmental variable, 'Amy' was more susceptible to low-light stress than 'Lilo' (Fig. 2). After several weeks of shade treatment, abscission in 'Amy' was much greater in low light than in high light while abscission in 'Lilo' was not significantly different between the treatments.

Total chlorophyll levels in leaves below (Fig. 3A) and above (Fig. 3D) the pinch were higher in 'Lilo' than in 'Amy' during the postproduction period. 'Lilo' responded to the low-light environment by maintaining (below the pinch) or even slightly increasing (above the pinch) the chlorophyll content. In contrast, 'Amy' in low light did not exhibit enhanced chlorophyll levels either below or above the pinch.

At the start of the postproduction period, the chlorophyll a : 


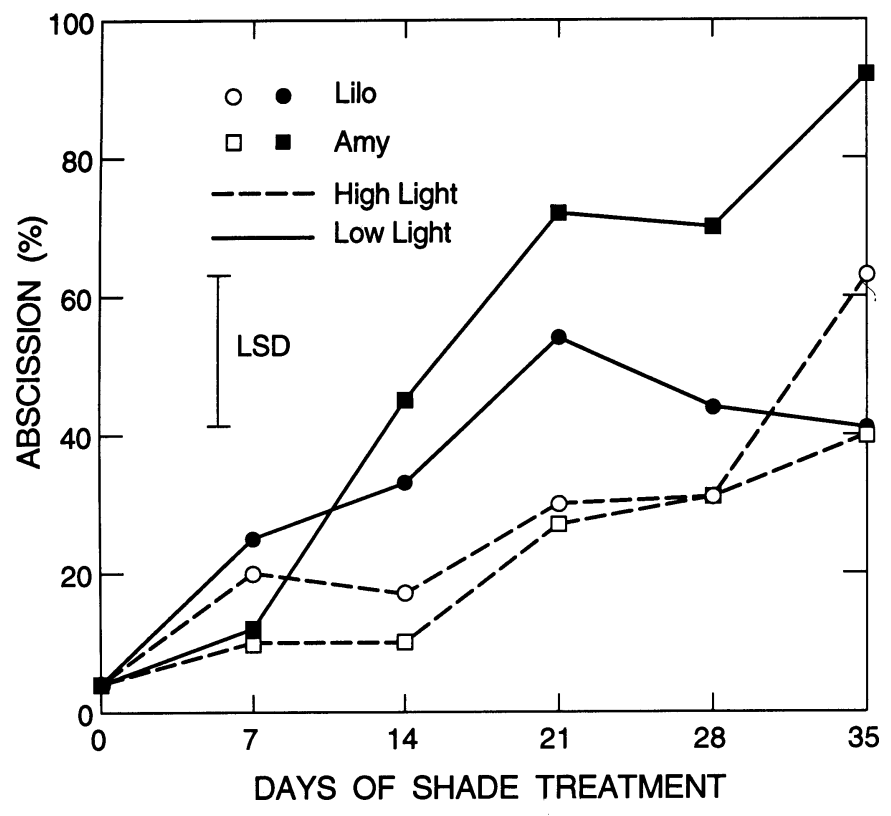

Fig. 2. Time course of effect of light level on abscission of main stem leaves below the pinch of postproduction poinsettias. At 0 days on the abscissa, the low-light plants were moved into the shade boxes while the high-light plants remained on an open bench. As necessitated by the destructive sampling for pigment quantitation and fluorescence measurements, separate lots of plants were used for each time point. Thus, apparent declines in abscission with time, as for 'Lilo' low-light plants between 21 and 35 days, were due to variations between the lots rather than to an impossible reversal of abscission. The LSD was calculated at $P=0.05$. chlorophyll b ratios in thylakoids from leaves below and above the pinch were slightly lower in 'Lilo' than in 'Amy' ( 0 days in Fig. 3 $B$ and E). As the shade treatment progressed, both 'Lilo' and 'Amy' had lower chlorophyll a : chlorophyll b ratios and higher chlorophyll : carotenoid ratios in low light than in high light.

The chlorophyll fluorescence excitation spectrum for thylakoids from 'Lilo' leaves showed strong bands in the violet to blue wavelengths of 400 to $500 \mathrm{~nm}$ and in the red wavelengths of 600 to $700 \mathrm{~nm}$ (Fig. 4A). These bands arise as the sum of lightharvesting contributions from each of the effective photosynthetic pigments in the thylakoid membranes. Chlorophyll a absorbance in thylakoid membranes is most prominent in Soret bands peaking in the wavelength regions of 430 to $440 \mathrm{~nm}$ and in first excited state bands peaking at 670 to $680 \mathrm{~nm}$. Chlorophyll b absorbance is similarly most prominent in a band peaking from 460 to $480 \mathrm{~nm}$ and in a weaker band peaking $\approx 650 \mathrm{~nm}$. The shorter wavelength bands of the chlorophylls are strongly overlapping with the absorbance by carotenoids, which peaks from 420 to $500 \mathrm{~nm}$ and is relatively prominent around $487 \mathrm{~nm}$ in thylakoid membranes (Sauer and Calvin, 1962; Siefermann-Harms, 1985, 1987).

These characteristic wavelengths for each type of pigment were used to assign the origins of the peaks and valleys appearing in fluorescence excitation difference spectra. The difference spectrum of 'Amy' minus 'Lilo' at the start of the postproduction period (Fig. 4B) exhibited a valley near $650 \mathrm{~nm}$, a wavelength of peak absorbance by chlorophyll $b$. This valley indicated relatively less light harvesting by chlorophyll b in 'Amy', a result consistent with the lower chlorophyll a : chlorophyll b content ratio in 'Lilo' than in 'Amy' at this time (0 days in Fig. 3B).



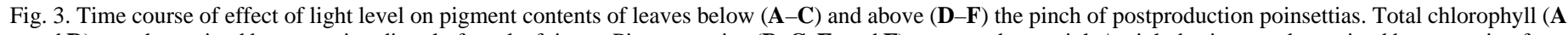

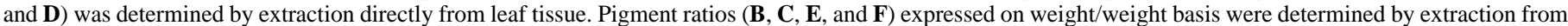
thylakoids to enable closest comparison with chlorophyll fluorescence excitation (Figs. 4-6). The LSD values were calculated at $P=0.05$. 




Fig. 4. Excitation of chlorophyll fluorescence in thylakoid membranes from leaves below the pinch of poinsettias. The spectra were recorded from 0-day samples as indicated in Fig. 3. (A) 'Lilo'. (B) Difference spectrum, 'Amy' minus 'Lilo'. The curve in (A) is a relative action spectrum showing how strongly chlorophyll fluorescence is generated by each wavelength of incident light. If 'Amy' and 'Lilo' were identical in this regard, then the curve in $\mathbf{B}$ would lie directly on the flat horizontal line shown at 0 on the ordinate.

Another important valley in the 'Amy' minus 'Lilo' difference spectrum (Fig. 4B) spanned the 455- to 500-nm region. Assignment of the origin of this band could not be made with certainty because absorbance bands of chlorophyll $b$ (460 to $480 \mathrm{~nm}$ ) and carotenoids ( 420 to $500 \mathrm{~nm}$ ) both peak in this region. Since the 460 to $480-\mathrm{nm}$ absorbance band of pure chlorophyll $\mathrm{b}$ is roughly twice as strong as its 650-nm band (Lichtenthaler, 1987), the relative sizes of the valleys in Fig. 4B were such that the 455- to 500-nm valley could have been due almost entirely to chlorophyll $b$. The likelihood of a contribution by carotenoid pigments to this valley seems further diminished by the lack of a statistically significant difference in the chlorophyll to carotenoid content ratios for 'Amy' and 'Lilo' at this time (0 days in Fig. 3C).

Low-light minus high-light difference spectra of chlorophyll fluorescence excitation consistently exhibited a peak near $650 \mathrm{~nm}$, demonstrating the effects of low-light stress during the postproduction period (Fig. 5). This peak indicated relatively more light harvesting by chlorophyll $\mathrm{b}$ in low light than in high light, a result consistent with the higher chlorophyll $\mathrm{a}$ : chlorophyll $\mathrm{b}$ content ratios in high light than in low light (Fig. $3 \mathrm{~B}$ and E). The difference spectra also consistently exhibited a broad peak in the 455- to 500-nm region of chlorophyll $b$ and carotenoid absorbance. Comparison of the difference spectra at 7 days (Fig. 5, A-D) and 35 days (Fig. 5, E-H) of shade treatment showed that larger differences appeared sooner in leaves above the pinch than in leaves below the pinch of 'Amy' and 'Lilo'. These low-light minus high-light difference spectra alone, however, did not reveal whether the changes with time were due to changes in the low-light plants or changes in the high-light plants, or both.

The time course of changes in chlorophyll fluorescence excitation were revealed by 35-day minus 0 -day difference spectra (Fig. 6). High-light plants (Fig. 6, A-D) consistently exhibited valleys at the $650 \mathrm{~nm}$ chlorophyll b band and at the 455 to $500 \mathrm{~nm}$ chlorophyll b/carotenoid band. These differences indicated gradual decreases in relative light harvesting by chlorophyll $b$, consistent with the observed tendencies of the chlorophyll a : chlorophyll b content ratios to increase in high-light plants (Fig. 3 B and E). In 'Lilo' the change was slightly greater in leaves below the pinch (Fig. 6A) than in leaves above the pinch (Fig. 6C), while in 'Amy' the change was larger above the pinch (Fig. 6D) than below the pinch (Fig. 6B). The difference spectra for low-light plants exhibited peaks at the $650 \mathrm{~nm}$ chlorophyll b band for 'Amy' leaves below the pinch (Fig. 6F) and 'Lilo' leaves above the pinch (Fig. 6G), but very little change in either 'Lilo' leaves below the pinch (Fig. 6E) or 'Amy' leaves above the pinch (Fig. 6H).

Chlorophyll fluorescence excitation spectra were recorded at 7day intervals throughout the 35-day postproduction period. Since changes in these spectra generally occurred gradually with time, only spectra from early and late in the period were presented (Figs. 5 and 6).

\section{Discussion}

The results of this study demonstrate that acclimatization occurred in the photosynthetic light-harvesting system of poinsettias exposed to low-light stress during the postproduction period, and that certain aspects of this acclimatization differed between the two cultivars. Changes in pigment contents exhibited by both 'Amy' and 'Lilo' resulted in lower chlorophyll a : chlorophyll b ratios (Fig. $3 \mathrm{~B}$ and $\mathrm{E}$ ) and higher total chlorophyll : carotenoid ratios (Fig. $3 \mathrm{C}$ and $\mathrm{F}$ ) in low light than in high light. As probed by chlorophyll fluorescence excitation spectra (Figs. 5 and 6), the light-harvesting function of the photosynthetic system consistently reflected these changes in chlorophyll a : chlorophyll b ratio, while the functional effects of changes in the chlorophyll : carotenoid ratio were not so clearly discernible.

These changes in pigment ratios in low-light poinsettias are very similar to changes observed in studies of other plants exposed to low-light stress (Anderson and Thomson, 1989; Lichtenthaler, 1987; Lichtenthaler et al., 1982, 1983; Nurmi, 1990; Wild et al., 1986). These studies have shown that plants acclimatize to low light by increasing the amount of light-harvesting complex II protein relative to the amount of reaction center proteins. Under low and moderate light levels, light-harvesting complex II is predominantly associated with photosystem II where it functions as a light-absorbing antenna (Gounaris et al., 1986). Since lightharvesting complex II contains most of the chlorophyll b in chloroplasts, an increase in the amount of this pigment-protein complex relative to the reaction center pigment-protein complexes leads to the commonly observed decrease in the chlorophyll a : chlorophyll b ratio in low light (Lichtenthaler, 1987). The relative increase in light-harvesting complex II may also be responsible for the commonly observed increase in the total chlorophyll : carotenoid ratio because while light-harvesting complex II binds chlorophyll and carotenoid pigments, its chlorophyll a: $\beta$-carotene content ratio is very high compared to the ratios for reaction center complexes (Lichtenthaler, 1987).

Regarding the comparison of 'Amy' and 'Lilo', the generally higher chlorophyll content of 'Lilo' (Fig. 3 A and D) and the resulting greater absorbance of light may contribute to the superior performance of 'Lilo' in interior environments. It is likewise 
7 DAYS


$+14$

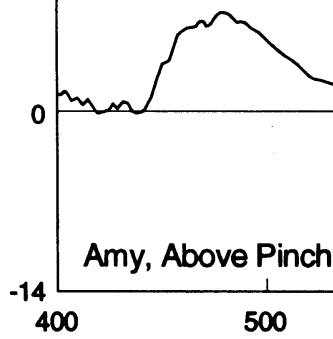

35 DAYS
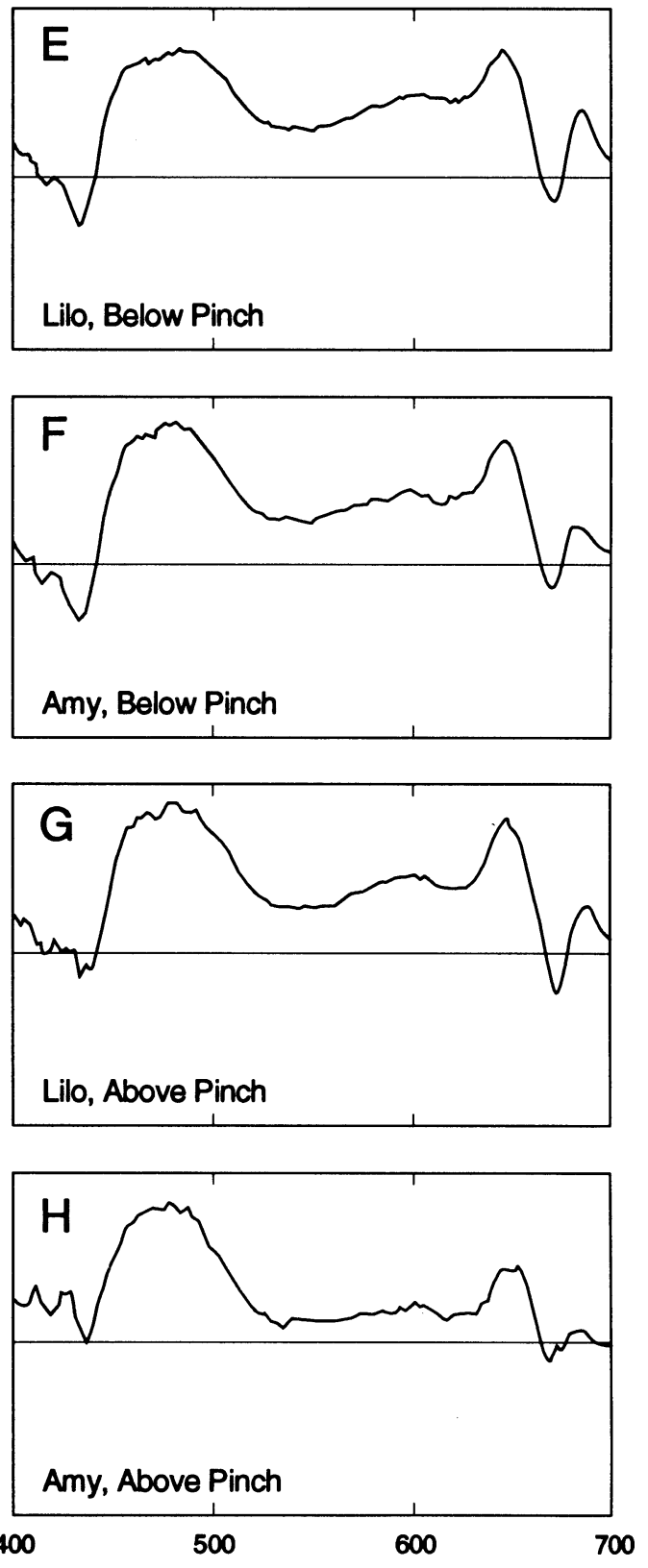

WAVELENGTH $(\mathrm{nm})$

Fig. 5. Effect of light level on the chlorophyll fluorescence excitation spectrum at (A-D) 7 days and (E-H) 35 days after the start of the shade treatment in the postproduction period of poinsettias. Each curve is a difference spectrum obtained by subtracting the excitation spectrum for high-light plants from the corresponding excitation spectrum for low-light plants.

relevant that low-light 'Lilo' plants were able to retain (below the pinch) or even accumulate (above the pinch) more chlorophyll than high-light plants, while 'Amy' did not exhibit this effect (Fig. $3 \mathrm{~A}$ and $\mathrm{D})$.

The lower initial chlorophyll a : chlorophyll b ratio in 'Lilo' (0 days, Fig. 3 B and E) may indicate that 'Lilo' is also predisposed to better performance in low light because its relative content of light-harvesting complex II is higher than that of 'Amy', although it would be necessary to directly measure pigment-protein contents in both cultivars to test this hypothesis.

As judged by chlorophyll fluorescence excitation, low-light acclimatization of light-harvesting function in both 'Amy' and 'Lilo' appeared sooner in leaves above the pinch than in leaves below the pinch (Fig. 5). While it seemed reasonable to conjecture that this earlier acclimatization above the pinch occurred because these younger leaves were more able to alter their metabolism in low light, further examination revealed that several different patterns all led to the appearance of net acclimatization (Fig. 6). With leaves above the pinch of 'Amy', for example, the change with time occurred mostly in high-light (Fig. 6D) rather than in low-light (Fig. 6H) leaves. In this case, net acclimatization (Fig. $5 \mathrm{H})$ resulted because the low-light plants simply maintained their original (day 0) excitation spectrum while the high-light plants changed their excitation spectrum with age.

The information gained in this study may prove useful in poinsettia breeding and evaluation programs. In particular, the 
HIGH LIGHT

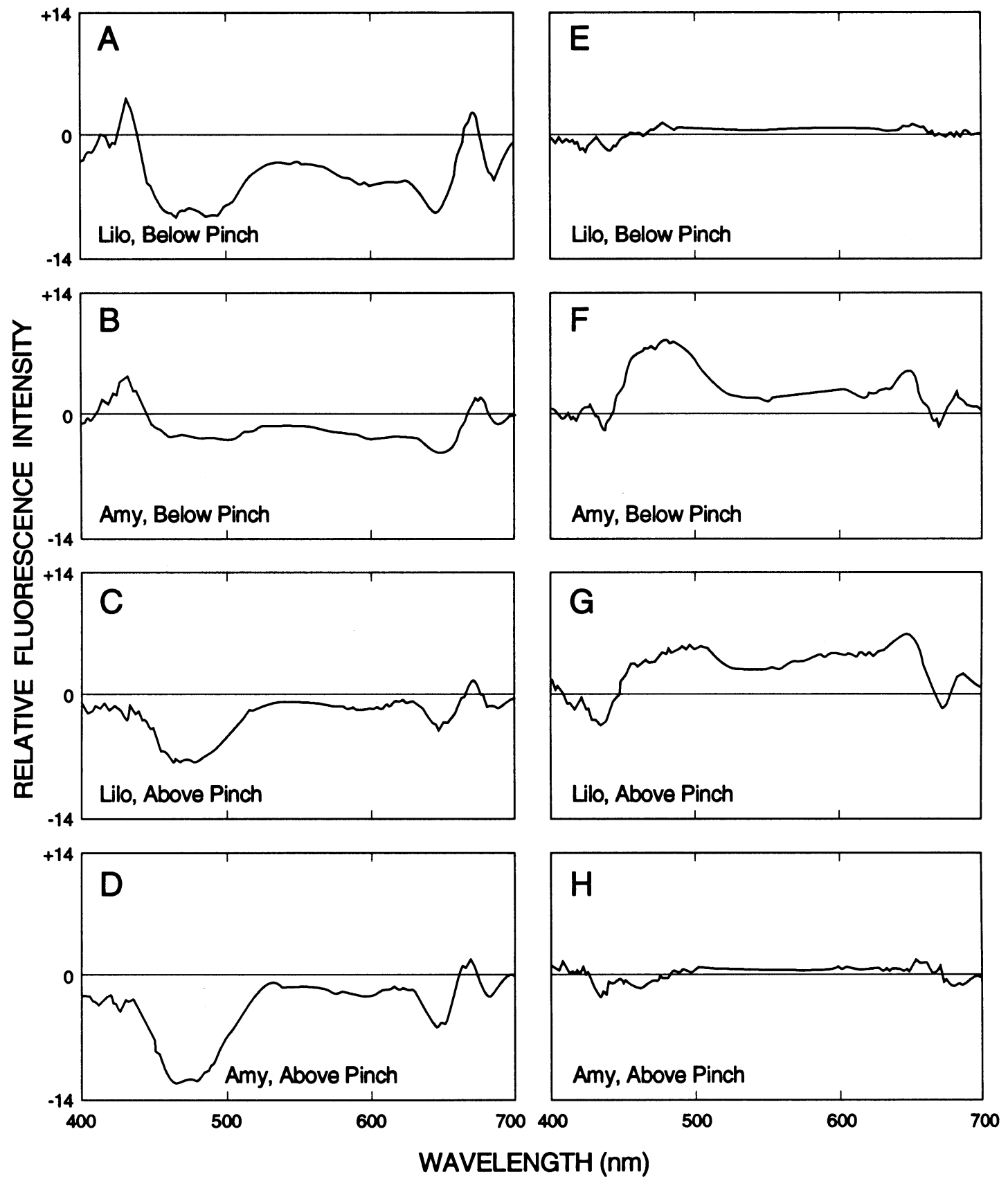

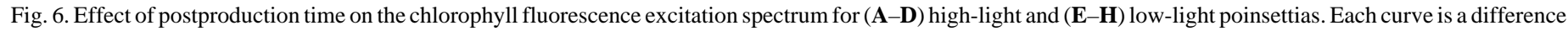
spectrum obtained by subtracting the excitation spectrum at 0 days from the corresponding excitation spectrum at 35 days.

results suggest that cultivars with high total chlorophyll content per leaf area and low chlorophyll a : chlorophyll b ratio may be inclined toward improved interior longevity. Measurements of these leaf pigment levels, which are relatively easy compared to measurements of fluorescence excitation, might prove useful as an early predictor of postproduction performance.

\section{Literature Cited}

Anderson, J.M. and W.W. Thomson. 1989. Dynamic molecular organization of the plant thylakoid membrane, p. 161-182. In: W.R. Briggs (ed.). Photosynthesis. Liss Press, New York.

Bailey, D.A. and W.B. Miller. 1991. Poinsettia developmental and postproduction responses to growth retardants and irradiance.
HortScience 26:1501-1503.

Butler, W.L. 1961. Chloroplast development, energy transfer and structure. Arch. Biochem. Biophys. 92:287-295.

Dowdy, S. and S. Weardon. 1983. Statistics for research. John Wiley and Sons, New York.

Embry, J.L. and E.A. Nothnagel. 1988. Leaf development and senescence in Panicum miliaceum L., a cereal with a short seed-to-seed cycle. Plant Sci. 55:129-136.

Fradkin, L.I., A.G. Samoilenko, and A.A. Shlyk. 1985. Development of energy transfer from carotenoids to chlorophyll a during the Shibata shift. Doklady Biophysics 281:100-103.

Goedheer, J.C. 1965. Fluorescence action spectra of algae and bean leaves at room and at liquid nitrogen temperatures. Biochim. Biophys. Acta 102:73-89. 
Goedheer, J.C. 1972. Fluorescence in relation to photosynthesis. Annu. Rev. Plant Physiol. 23:87-112.

Gounaris, K., J. Barber, and J.L. Harwood. 1986. The thylakoid membranes of higher plant chloroplasts. Biochem. J. 237:313-326.

Hipkins, M.F. and N.R. Baker. 1986. Spectroscopy, p. 51-101. In: M.F. Hipkins and N.R. Baker (eds.). Photosynthesis and energy transduction, a practical approach. IRL Press, Oxford, U.K.

Koizumi, M., H. Kano, N. Katsura, and K. Inada. 1990. The effect of chlorophyll content on changes of photochemical reactions in intact kidney bean leaves. Plant Cell Environ. 13:65-71.

Lichtenthaler, H.K. 1987. Chlorophylls and carotenoids: Pigments of photosynthetic biomembranes. Methods Enzymol. 148:350-382.

Lichtenthaler, H.K., R. Burgstahler, C. Buschmann, D. Meier, U. Prenzel, and A. Schonthal. 1983. Effect of high light and high light stress on composition, function and structure of the photosynthetic apparatus, $p$. 353-370. In: R. Marcelle, H. Clijsters, and M. Van Poucke (eds.). Effects of stress on photosynthesis. Martinus Nijhoff Publishers, Boston, Mass.

Lichtenthaler, H.K., G. Kuhn, U. Prenzel, C. Buschmann, and D. Meier. 1982. Adaptation of chloroplast-ultrastructure and of chlorophyll-protein levels to high-light and low-light growth conditions. Z. Naturforsch. $37 \mathrm{c}: 464-475$.

Miller, S.H. and R.D. Heins. 1986a. Factors influencing premature cyathia abscission in poinsettia 'Annette Hegg Dark Red.' J. Amer. Soc. Hort. Sci. 111:114-121.

Miller, S.H. and R.D. Heins. 1986b. Variation in cyathia abscission of poinsettia cultivars in a greenhouse and a simulated postharvest environment. HortScience 21:270-272.

Nell, T.A. and J.E. Barrett. 1986. Production light level effects on light compensation point, carbon exchange rate and postproduction longevity of poinsettias. Acta Hort. 181:257-262.

Nell, T.A. and J.E. Barrett. 1990. Where are we in improving flowering potted plant quality and longevity? Res. Rpt. Amer. Floral Endowment 2(1):1-8.

Nell, T.A., R.T. Leonard, and J.E. Barrett. 1990. Production and postproduction irradiance affects acclimatization and longevity of potted chrysanthemum and poinsettia. J. Amer. Soc. Hort. Sci. 115:262-265.

Nothnagel, E.A. 1987. Quantum counter for correcting fluorescence excitation spectra at $320-$ to $800-\mathrm{nm}$ wavelengths. Anal. Biochem. 163:224-237.

Nurmi, A.H. 1990. Alteration of thylakoid membrane structure in Brassica rapa ssp. oleifera during ageing in high and low light. Plant Cell Environ. 13:305-317.

Percival, M.P. and N.R. Baker. 1985. Comparison of chlorophyll fluorescence emission characteristics of wheat leaf tissue and isolated thylakoids as a function of excitation wavelength. Plant Cell Environ. 8:41-48.

Sauer, K. and M. Calvin. 1962. Absorption spectra of spinach quantasomes and bleaching of the pigments. Biochim. Biophys. Acta 64:324-339.

Scott, L.F., T.M. Blessington, and J.A. Price. 1984a. Influence of controlled-release fertilizers, storage duration, and light source on postharvest quality of poinsettia. HortScience 19:111-112.

Scott, L.F., T.M. Blessington, and J.A. Price. 1984b. Postharvest effects of storage method and duration on quality retention of poinsettias. HortScience 19:290-291.

Shanks, J.B., W.E. Noble, and W.T. Witte. 1970. Influence of light and temperature upon leaf and bract abscission in poinsettia. J. Amer. Soc. Hort. Sci. 95:446-449.

Siefermann-Harms, D. 1985. Carotenoids in photosynthesis, I. Location in photosynthetic membranes and light-harvesting function. Biochim. Biophys. Acta 811:325-355.

Siefermann-Harms, D. 1987. The light-harvesting and protective functions of carotenoids in photosynthetic membranes. Physiol. Plant. 69:561568.

Vertucci, C.W., J.L. Ellenson, and A.C. Leopold. 1985. Chlorophyll fluorescence characteristics associated with hydration level in pea cotyledons. Plant Physiol. 79:248-252.

Wild, A., M. Hopfner, W. Ruhle, and M. Richter. 1986. Changes in the stoichiometry of photosystem II components as an adaptive response to high-light and low-light conditions during growth. Z. Naturforsch. 41c:597-603. 